\title{
Target Behaviours and Target-Directed Behaviours as Recall Cues in Person Memory
}

\section{J.-L. Beauvois and N. Dubois}

\section{(2) OpenEdition}

Journals

\section{Electronic version}

URL: http://journals.openedition.org/cpl/180

DOI: $10.4000 / \mathrm{cpl} .180$

ISSN: $1379-6100$

\section{Publisher}

Centre PsyCLÉ

\section{Printed version}

Date of publication: 1 April 2001

\section{Electronic reference}

J.-L. Beauvois and N. Dubois, «Target Behaviours and Target-Directed Behaviours as Recall Cues in Person Memory », Current psychology letters [Online], 2001/1, 4 | 2001, Online since 05 September 2003, connection on 08 September 2020. URL : http://journals.openedition.org/cpl/180 ; DOI : https:// doi.org/10.4000/cpl.180

This text was automatically generated on 8 September 2020.

(C) All rights reserved 


\section{Target Behaviours and Target- Directed Behaviours as Recall cues in Person Memory}

J.-L. Beauvois and N. Dubois 